Published in final edited form as:

Lancet Oncol. 2013 May ; 14(6): 472-480. doi:10.1016/S1470-2045(13)70095-0.

\title{
Safety and activity of crizotinib for paediatric patients with refractory solid tumours or anaplastic large-cell lymphoma: a Children's Oncology Group phase 1 consortium study
}

\author{
Yael P Mossé, MD, \\ Division of Oncology and Center for Childhood Cancer Research, Children's Hospital of \\ Pennsylvania, Philadelphia, PA, USA \\ Megan S Lim, MD, \\ Department of Pathology, University of Michigan, Ann Arbor, MI, USA \\ Stephan D Voss, MD, \\ Medical School, Boston, MA, USA \\ Keith Wilner, PhD, \\ Pfizer Oncology, La Jolla, CA, USA \\ Katherine Ruffner, MD, \\ Pfizer Oncology, La Jolla, CA, USA \\ Julie Laliberte, \\ Department of Pathology, University of Michigan, Ann Arbor, MI, USA \\ Delphine Rolland, \\ Department of Pathology, University of Michigan, Ann Arbor, MI, USA
}

Philadelphia, and Department of Pediatrics, Perelman School of Medicine at the University of

Department of Radiology, Boston Children's Hospital, Dana Farber Cancer Institute, Harvard

Prof. Frank M Balis, MD,

Division of Oncology and Center for Childhood Cancer Research, Children's Hospital of

Philadelphia, and Department of Pediatrics, Perelman School of Medicine at the University of

Pennsylvania, Philadelphia, PA, USA

Prof. John M Maris, MD,

Division of Oncology and Center for Childhood Cancer Research, Children's Hospital of

Philadelphia, and Department of Pediatrics, Perelman School of Medicine at the University of

Pennsylvania, Philadelphia, PA, USA

Brenda J Weigel, MD,

Division of Pediatric Oncology, University of Minnesota Cancer Center, Minneapolis, MN, USA

Ashish M Ingle, MS,

Children's Oncology Group Operations Center, Monrovia, CA, USA

\footnotetext{
Correspondence to: Dr Yael P Mossé, Children's Hospital of Philadelphia, 3501 Civic Center Blvd, CTRB 3056, Philadelphia, PA 19104, USA, mosse@chop.edu.

Contributors

All authors were responsible for the study design, data collection, data analysis, data interpretation, and writing of the report. All authors had full access to the final version of the report and agreed to the submission.

Conflicts of interest

KW and KR are both employees of Pfizer and stockholders at the company. The other authors declare that they have no conflicts of interest.
} 
Charlotte Ahern, PhD,

Texas Children's Cancer Center, Baylor College of Medicine, Houston, TX, USA

Prof. Peter C Adamson, MD, and

Division of Oncology and Center for Childhood Cancer Research, Children's Hospital of

Philadelphia, and Department of Pediatrics, Perelman School of Medicine at the University of

Pennsylvania, Philadelphia, PA, USA

Prof. Susan M Blaney, MD

Texas Children's Cancer Center, Baylor College of Medicine, Houston, TX, USA

\section{Summary}

Background-Various human cancers have $A L K$ gene translocations, amplifications, or oncogenic mutations, such as anaplastic large-cell lymphoma, inflammatory myofibroblastic tumours, non-small-cell lung cancer (NSCLC), and neuroblastoma. Therefore, ALK inhibition could be a useful therapeutic strategy in children. We aimed to determine the safety, recommended phase 2 dose, and antitumour activity of crizotinib in children with refractory solid tumours and anaplastic large-cell lymphoma.

Methods-In this open-label, phase 1 dose-escalation trial, patients older than 12 months and younger than 22 years with measurable or evaluable solid or CNS tumours, or anaplastic large-cell lymphoma, refractory to therapy and for whom there was no known curative treatment were eligible. Crizotinib was given twice daily without interruption. Six dose levels $(100,130,165$, $215,280,365 \mathrm{mg} / \mathrm{m}^{2}$ per dose) were assessed in the dose-finding phase of the study (part A1), which is now completed. The primary endpoint was to estimate the maximum tolerated dose, to define the toxic effects of crizotinib, and to characterise the pharmacokinetics of crizotinib in children with refractory cancer. Additionally, patients with confirmed $A L K$ translocations, mutations, or amplification (part A2 of the study) or neuroblastoma (part A3) could enrol at one dose level lower than was currently given in part A1. We assessed $A L K$ genomic status in tumour tissue and used quantitative RT-PCR to measure $N P M-A L K$ fusion transcript in bone marrow and blood samples of patients with anaplastic large-cell lymphoma. All patients who received at least one dose of crizotinib were evaluable for response; patients completing at least one cycle of therapy or experiencing dose limiting toxicity before that were considered fully evaluable for toxicity. This study is registered with ClinicalTrials. gov, NCT00939770.

Findings - 79 patients were enrolled in the study from Oct 2, 2009, to May 31, 2012. The median age was 10.1 years (range 1.1-21.4); 43 patients were included in the dose escalation phase (A1), 25 patients in part A2, and 11 patients in part A3. Crizotinib was well tolerated with a recommended phase 2 dose of $280 \mathrm{mg} / \mathrm{m}^{2}$ twice daily. Grade 4 adverse events in cycle 1 were neutropenia (two) and liver enzyme elevation (one). Grade 3 adverse events that occurred in more than one patient in cycle 1 were lymphopenia (two), and neutropenia (eight). The mean steady state peak concentration of crizotinib was $630 \mathrm{ng} / \mathrm{mL}$ and the time to reach this peak was $4 \mathrm{~h}$ (range 1-6). Objective tumour responses were documented in 14 of 79 patients (nine complete responses, five partial responses); and the anti-tumour activity was enriched in patients with known activating $A L K$ aberrations (eight of nine with anaplastic large-cell lymphoma, one of 11 with neuroblastoma, three of seven with inflammatory myofibroblastic tumour, and one of two with NSCLC).

Interpretation-The findings suggest that a targeted inhibitor of ALK has antitumour activity in childhood malignancies harbouring $A L K$ translocations, particularly anaplastic large-cell lymphoma and inflammatory myofibroblastic tumours, and that further investigation in the subset of neuroblastoma harbouring known $A L K$ oncogenic mutations is warranted.

Funding_Pfizer and National Cancer Institute grant to the Children's Oncology Group. 


\section{Introduction}

The $A L K$ oncogene is a promising therapeutic target in a subset of human malignancies. $A L K$, an orphan receptor tyrosine kinase (RTK) usually expressed in the developing nervous system, ${ }^{1}$ was originally cloned from a cytogenetically recognisable translocation between chromosomes 2 and 5 that fused the kinase domain of $A L K$ to the protein dimerisation domain of $N P M{ }^{2}$ Over a dozen $A L K$ fusion partners have since been identified including $R A N B P 2$ in inflammatory myofibroblastic tumour, ${ }^{3,4} E M L 4$ in 3-7\% of non-small-cell lung cancers (NSCLCs), ${ }^{5}$ and TPM3 in renal cancer. ${ }^{6}$ The discovery of activating mutations in the tyrosine kinase domain of the $A L K$ oncogene as the most common cause of hereditary neuroblastoma, and the finding that these mutations are also somatically acquired in 7-10\% of sporadic cases, provides a tractable molecular target. ${ }^{7-10}$ Others have suggested an oncogenic role for overexpressed but non-mutated $A L K$ in lung cancer,${ }^{11}$ thyroid cancer (rare mutations identified), ${ }^{12}$ glioblastoma multiforme, ${ }^{13}$ and rhabdomyosarcoma. ${ }^{14}$

Crizotinib, a small molecule competitive inhibitor of ALK and MET kinase activity, has transformed the therapeutic landscape of NSCLC harbouring $A L K$ translocations, yielding high response rates in chemotherapy-refractory patients. ${ }^{15,16}$ Crizotinib has also shown efficacy, such as high cytoreductive antitumour activity, in preclinical models of neuroblastoma ${ }^{17}$ and anaplastic large-cell lymphoma ${ }^{18}$ that express activated translocated, mutated, or amplified $A L K$. These combined data have provided the rationale for ALK inhibition as a useful therapeutic strategy in neuroblastoma, anaplastic large-cell lymphoma, and potentially other paediatric tumours.

We aimed to study the safety, recommended phase 2 dose, and antitumour activity of crizotinib in children with refractory solid tumours and anaplastic large-cell lymphoma.

\section{Methods}

\section{Study design and participants}

Children's Oncology Group (COG) study ADVL0912 had three primary aims: (1) to estimate the maximum tolerated dose and recommended phase 2 dose of crizotinib given orally twice daily to children with relapsed or refractory solid tumours and anaplastic largecell lymphoma; (2) to define and describe the toxic effects of crizotinib given on this schedule; and (3) to characterise the pharmacokinetics of crizotinib in children with refractory cancer. Secondary endpoints included examining best disease response to treatment and minimal residual disease monitoring. This trial had three parts: A1, the phase 1 , was the dose escalation component for patients with relapsed or refractory solid tumours or anaplastic large-cell lymphoma; A2 included an expanded cohort of patients with confirmed ALK or MET fusion proteins, mutations, or amplification; and A3 included a cohort of patients with neuroblastoma not fulfilling the eligibility criteria for A1 because of intensive previous therapy, or not able to enrol on part A1 of the study because of stratum suspension or no available spots.

Patients older than 12 months and younger than 22 years with measurable or evaluable solid or CNS tumours, or anaplastic large-cell lymphoma, refractory to therapy and for whom there was no known curative treatment were eligible. To be included in part A2 of the study, patients had to have confirmed $A L K$ translocations, activating mutations, or amplification (defined as greater than four-fold increase in the $A L K$ signal number as compared with reference signal number on chromosome $2 \mathrm{q}$ ) performed as a Clinical Laboratory Improvement Amendments (CLIA) certified assay. ALK immunohistochemistry could be used as a surrogate for FISH in patients with anaplastic large-cell lymphoma, or inflammatory myofibroblastic tumours. To be included in part A3 of the study, patients had 
to have neuroblastoma, with or without bone marrow involvement. Patients in all three parts of the study could not have received previous cytotoxic chemotherapy within 3 weeks before enrolment and had to have recovered from the acute toxic effects of previous therapy before initiation of crizotinib. Patients with CNS tumours or known CNS metastases were excluded after two patients in part A1 had intratumoral haemorrhage.

Patients were required to have a Karnofsky (those older than 16 years) or Lansky (those younger than 16 years) performance score of at least 50. Patients had to have adequate bone marrow (patients in the dose escalation group without bone marrow involvement had to have absolute neutrophil count $\geq 1000$ cells per $\mu \mathrm{L}$, platelet count $\geq 75000$ cells per $\mu \mathrm{L}$, and haemoglobin $\geq 80 \mathrm{~g} / \mathrm{L}$; patients with bone marrow metastatic disease, as well as patients in the other two groups, had to have absolute neutrophil count $\geq 750$ cells per $\mu \mathrm{L}$, platelet count $\geq 25000$ cells per $\mu \mathrm{L}$, and haemoglobin $\geq 80 \mathrm{~g} / \mathrm{L}$ ), renal (normal serum creatinine for age), hepatic (total bilirubin $\leq 15 \times$ normal and alanine aminotransferase $5 \cdot 0 \times$ xupper limit of normal (ULN—for this study, the ULN was $45 \mathrm{U} / \mathrm{L}$ ), and cardiac (QTc $\$ 480 \mathrm{~ms}$ ) function. Patients also could not have received palliative radiation within 2 weeks or radiation to more than $50 \%$ of the pelvis or craniospinal axis within 6 months; or biological therapy or growth factors within 7 days or autologous stem-cell transplantation within 3 months (previous allogeneic transplantation was an exclusion criteria) of enrolment. Exclusion criteria also included uncontrolled infection, pregnancy or lactation, and concurrent administration of some P-glycoprotein substrates.

The institutional review boards of participating institutions approved the protocol. Written informed consent from parents or guardians and assent, as appropriate, were obtained according to local institutional guidelines. Source documents are verified on site at a regular basis for all patients enrolled at COG phase 1 and consortium sites.

\section{Procedures}

Patients received crizotinib given orally twice daily on a continuous schedule in cycles of 28 days duration. Study drug was initially supplied as capsules $(10 \mathrm{mg}, 50 \mathrm{mg}$, or $100 \mathrm{mg}$ ) and a dosing nomogram was used to minimise interpatient dosing variability (appendix). An oral liquid formulation $(25 \mathrm{mg} / \mathrm{mL})$ was subsequently developed for children unable to swallow capsules. The liquid formulation was given at the same dose as the capsule formulation on the basis of the results of bioequivalence studies in adults (personal communication, Keith Wilner, Pfizer). Nine patients received the liquid formulation.

We assessed six dose-levels $\left(100,130,165,215,280\right.$, and $365 \mathrm{mg} / \mathrm{m}^{2}$ per dose) in part A1 using a rolling-six design. ${ }^{19}$ Since we did not expect haematological toxic effects to be a dose-limiting toxicity (DLT), up to one patient in each cohort of part A1 could have bone marrow involvement. The initial crizotinib dose level was $80 \%$ of the adult maximum tolerated dose, and each subsequent dose escalation was incrementally increased by about $30 \%$.

Patients enrolled to the other parts of the study (A2 and A3) received crizotinib at one dose level lower than that undergoing assessment in A1; we permitted a single intra-patient dose escalation to the next highest dose level for these patients when the A1 dose level did not exceed the maximum tolerated dose. A prospective stopping rule for toxic effects precluded further enrolment onto part A2 if more than a third of patients experienced a DLT. A maximum of three patients could enrol onto part A3 at every dose level and if two of three patients experience a DLT in that part, further enrolment was precluded.

Toxic effects were graded according to the Common Terminology Criteria for Adverse Events version 4.0. We defined haematological DLT as crizotinib-related grade 4 
thrombocytopenia or grade 4 neutropenia. We defined non-haematological DLT as any grade 3 or 4 non-haematological toxic effect possibly, probably, or definitely attributable to crizotinib with the exception of the following grade 3 toxic effects: nausea or vomiting that resolved within 3 days, fever, infection, or serum mineral or electrolyte disturbances that resolved with oral supplementation. We deemed dose limiting any toxic effects that resulted in a treatment delay of more than 14 days. The maximum tolerated dose was exceeded if two or more patients in a cohort of two-to-six patients experienced a DLT during cycle 1.

For patients with anaplastic large-cell lymphoma, we made serial assessments of the NPM$A L K$ fusion transcript at translocation $\mathrm{t}(2 ; 5)$ (p23; $\mathrm{q} 35)$. We obtained baseline bone marrow and blood samples, as well as peripheral blood samples on day 15 of cycle 1, day 1 of cycle 2 , and then once during each subsequent cycle during routine lab assessments. We did quantitative RT-PCR to assess minimal residual disease; total RNA was extracted from bone marrow or serial peripheral blood specimens, or both, for detection of the $\mathrm{t}(2 ; 5)(\mathrm{p} 23 ; \mathrm{q} 35)$ $N P M-A L K$ fusion transcript. The normalised copy numbers (NCN) were expressed as copy numbers of $N P M-A L K$ per $10^{4}$ copies of $A B L$ as previously published. ${ }^{20}$

For the patients with neuroblastoma, when tumour tissue was available from either diagnosis or relapse, we did comprehensive DNA sequencing of the $A L K$ tyrosine kinase domain using Sanger-based sequencing. In the absence of frozen tissue, we submitted unstained slides from archived tumour tissue for determination of ALK immunohistochemistry, and FISH for determination of $A L K$ copy number status. We did not obtain information of $M Y C N$ amplification, because it did not relate to any of the primary or secondary aims of the study.

\section{Pharmacokinetic and response assessment analyses}

We undertook pharmacokinetic sampling at steady state (day 15-28 of continuous twice daily dosing). Blood samples of $2 \mathrm{~mL}$ were drawn into ethylenediaminetetraacetic acid (EDTA) containing tubes before the dose (12 h after the previous dose) and $1 \mathrm{~h}, 2 \mathrm{~h}, 4 \mathrm{~h}$, and $6-8 \mathrm{~h}$ after the dose. Samples were protected from light and placed on ice; and plasma was separated by centrifugation and stored at $-20^{\circ} \mathrm{C}$ to $-70^{\circ} \mathrm{C}$ until assayed. We measured crizotinib in plasma samples using a validated HPLC tandem mass spectrometry assay (concentration range of quantitation $0 \cdot 2-200 \mathrm{ng} / \mathrm{mL}$ ). We derived the steady state area under the plasma concentration-time curve for the $12 \mathrm{~h}$ dosing interval ( $\mathrm{AUC}^{\mathrm{SS}}{ }_{0-12 \mathrm{~h}}$ ) using the trapezoidal method. We deemed the trough crizotinib concentration $\left(\mathrm{C}^{\mathrm{SS}}{ }_{12 \mathrm{~h}}\right)$ after the dose to be equal to the pre-dose concentration. We derived the steady state average concentration $\left(\mathrm{C}^{\mathrm{SS}}{ }_{A V E}\right)$ by dividing the $\mathrm{AUC}^{\mathrm{SS}}{ }_{0-12 \mathrm{~h}}$ by $12 \mathrm{~h}$ (the dosing interval).

\section{Efficacy analyses}

We did disease assessments at baseline, before cycle 2, every other cycle three times, and then every three cycles. Patients with non-CNS solid tumours other than anaplastic large-cell lymphoma had their disease assessed following RECIST 1.0 criteria for response assessment. We measured up to ten target lesions. Complete response was no residual disease; we defined partial response as shrinkage of measurable disease by $30 \%$ or more. We did the response assessment for patients with neuroblastoma with non-measurable disease detectable by MIBG scintigraphy using Curie scoring ${ }^{21}$ to quantitate overall disease burden. We assessed the disease of patients with anaplastic large-cell lymphoma using International Working Group (IWG) criteria for response and relied on bidirectional measurements of up to ten lesions. Except for confirming complete response, we did not use 18-fluorodeoxyglucose (FDG) PET results for analysis of response. As per IWG guidelines, complete response was no residual disease; unconfirmed complete response $(\mathrm{CRu})$ was defined as more than $75 \%$ shrinkage of the sums of the perpendicular diameters and no 
residual FDG PET activity; partial response was decrease of 50\% or more in the sums of the perpendicular diameters of the lesions with no new lesions.

In all cases, we defined stable disease as failing to meet criteria for either partial response or complete response. We based progressive disease on appearance of new lesion(s), an increase of $20 \%$ or more in tumour size by RECIST, or an increase of $25 \%$ or greater in tumour size by IWG criteria. We still deemed patients with disease that could not be accurately measured in at least one dimension to have evaluable disease, since disease could be assessed by other non-radiographic techniques. Responses had to be sustained for a minimum of two consecutive imaging assessments at least 4 weeks apart. Imaging studies for patients with a reported objective response or prolonged stable disease (six or more cycles) underwent central radiographic review for confirmation of response. This study is registered with ClinicalTrials.gov, NCT00939770.

\section{Role of the funding source}

Both funding sources contributed to the study design through scientific review. Pfizer provided crizotinib, funding for correlative pharmacokinetic and correlative biology studies, as well as infrastructure support. All authors participated in the writing of the report and had full access to the raw data. The corresponding author had full access to all the data in the study and had final responsibility for the decision to submit for publication.

\section{Results}

79 patients with a median age of $10 \cdot 1$ years (range $1 \cdot 1-21 \cdot 4$ ) were enrolled in the study from Oct 2, 2009, to May 31, 2012 (table 1); all were eligible for enrolment and began therapy, and 65 were fully evaluable for DLT. 14 patients were not fully evaluable for toxic effects, mainly because of disease progression before completion of the first cycle (12 from the dose escalation group, and one each in the other two groups in the study). Eight of the patients in the neuroblastoma group were not evaluable for haematological toxic effects because of bone marrow involvement with tumour. Table 1 shows patient characteristics and additional information about study aims and patient eligibility are shown in the appendix. The median number of cycles received until Feb 1, 2013, in these 79 patients is 3 (IQR 1-9), with 13 patients still receiving protocol therapy. The median number of cycles received is 2 (IQR 13.5 ) in the dose escalation group (four remain on therapy), 7 (IQR 3-16) in the confirmed genetic alteration group (nine on therapy) and 1 (IQR 1-4) in the neuroblastoma group (none remain on protocol therapy).

Crizotinib was escalated in cohorts of patients from $100 \mathrm{mg} / \mathrm{m}^{2}$ per dose twice daily to 365 $\mathrm{mg} / \mathrm{m}^{2}$ per dose twice daily using the rolling-six design in the dose escalation part of the study. ${ }^{19}$ Table 2 shows crizotinib-related toxic effects and table 3 shows DLTs at every dose level. Additionally, the appendix shows all adverse events regardless of attribution. Two patients with primary brain tumours had intratumoral haemorrhage (intrinsic pontine glioma and grade 2 astrocytoma, $130 \mathrm{mg} / \mathrm{m}^{2}$ per dose and $215 \mathrm{mg} / \mathrm{m}^{2}$ per dose levels) considered unlikely (130 mg/m $\mathrm{m}^{2}$ per dose) and possibly $\left(215 \mathrm{mg} / \mathrm{m}^{2}\right.$ per dose) related to crizotinib. The trial was subsequently amended to exclude enrolment of patients with CNS tumours and subsequent dose escalation proceeded beyond the $215 \mathrm{mg} / \mathrm{m}^{2}$ per dose level after that dose was shown not to exceed the maximum tolerated dose in patients without CNS tumours. At the dose level of $365 \mathrm{mg} / \mathrm{m}^{2}$ per dose, we recorded two DLTs (table 3); thus the maximum tolerated dose or recommended phase 2 crizotinib dose for children with solid tumours, including lymphomas, was $280 \mathrm{mg} / \mathrm{m}^{2}$ per dose.

Crizotinib was overall well tolerated without evidence of cumulative toxic effects (table 2). During the first cycle of treatment mild nausea was reported by 42 patients $(65 \%)$, mild 
vomiting by 37 patients (57\%), and mild visual disturbances by 24 patients ( $37 \%$; table 2 ). Electrocardiographs were obtained at screening before enrolment and we recorded no adverse events indicative of cardiotoxic effects. Eight patients required dose reductions as a result of toxic effects for various reasons (appendix). Studies assessing potential bone toxic effects were incorporated into the phase 2 portion of this trial and are ongoing.

13 girls and five boys enrolled at the $280 \mathrm{mg} / \mathrm{m}^{2}$ per dose level had appropriate pharmacokinetic sampling at steady state. The median age of this pharmacokinetic subset was $10 \cdot 6$ years (IQR $8 \cdot 3-17.7$ years). The mean steady state peak concentration (C ${ }^{S S}$ MAX) was $630 \mathrm{ng} / \mathrm{mL}\left(\mathrm{CV} 34 \%\right.$ ), the $\mathrm{C}^{\mathrm{SS}} \mathrm{AVE}$ was $520 \mathrm{ng} / \mathrm{mL}(35 \%)$, and the $\mathrm{C}^{\mathrm{SS}}{ }_{12 \mathrm{~h}}$ was $420 \mathrm{ng} /$ $\mathrm{mL}(42 \%)$. The median time to $\mathrm{C}^{\mathrm{SS}} \mathrm{MAX}$ was $4 \mathrm{~h}$ (IQR 2-5·2). Pharmacokinetic data for all patients on this trial will be reported separately.

Nine patients with $A L K$-translocated anaplastic large-cell lymphoma were enrolled, all of whom received previous multiagent chemotherapy and one of whom had had a previous autologous bone marrow transplantation. We did not collect information about previous therapy with SGN-35 and vinblastine. Eight of the patients had measurable radiographic disease, six of whom had a complete response, one a partial response, and one had stable disease (table 4). Additionally, one patient with evaluable disease assessed by CT scan had a complete response (table 4).

Seven patients with $A L K$-translocated inflammatory myofibroblastic tumours were enrolled and treated (table 4). Six of the patients had measurable radiographic disease, three of whom had a partial response and another three had stable disease (table 4). The one patient with evaluable disease has had stable disease and treatment is ongoing. One patient with measurable disease had an infiltrative mass of the deltoid muscle and has received 2 years of crizotinib with a high decrease in tumour signal on MRI, and another patient with multiple pulmonary nodules had a partial response after cycle 1 .

Two patients, aged 17 and 21 years, with $A L K$-translocated NSCLC were enrolled at the $165 \mathrm{mg} / \mathrm{m}^{2}$ per dose level (table 4). One had stable disease for five cycles and the other had a partial response after cycle 3 of therapy but developed brain metastases after 16 cycles and was therefore removed from protocol therapy.

11 patients with neuroblastoma with known $A L K$ mutations were treated at doses ranging from $100 \mathrm{mg} / \mathrm{m}^{2}$ to $365 \mathrm{mg} / \mathrm{m}^{2}$ per dose (table 5). Of these patients, one had a complete response and two have stable disease. Two of these patients had germline mutations (both Arg $1275 \mathrm{Gln}$ ), one of whom had a positive family history of the disease. Although the patient with a family history of the disease $\left(165 \mathrm{mg} / \mathrm{m}^{2}\right.$ per dose level, with escalation to $215 \mathrm{mg} / \mathrm{m}^{2}$ ) has not met objective RECIST criteria for response, sites of ${ }^{123}$ I-MIBG-avid skeletal disease resolved and a neck mass became negative for ${ }^{123}$ I-MIBG uptake by cycle 7 of therapy. The other patient with a germline $A L K$ mutation achieved a complete response after cycle 3 of therapy, but subsequently had grade 3 elevation in alkaline phosphatase after cycle 7 , requiring removal from protocol therapy.

The other 23 patients enrolled with neuroblastoma had unknown $A L K$ status in their tumour and were treated at doses ranging between $100 \mathrm{mg} / \mathrm{m}^{2}$ per dose and $365 \mathrm{mg} / \mathrm{m}^{2}$ per dose (table 5). One patient had a complete response and received 26 cycles of drug. Five additional patients have had prolonged stable disease ranging from five to 39 cycles of therapy and three remain on treatment.

Of the 22 patients with other solid tumours and five with CNS tumours enrolled on this trial, seven patients had stable disease with diagnoses of: alveolar soft part sarcoma (one patient; six cycles), osteosarcoma (three patients; two, five, and nine cycles), malignant tumour of 
fusiform cell type (one patient; six cycles), neurilemoma (one patient; 19 cycles), and hepatocellular carcinoma (one patient; three cycles).

At the time of this report, we obtained RT-PCR data from 77 samples (eight pre-therapy bone marrow aspirates, five pre-therapy peripheral blood samples, one post-therapy bone marrow and 63 post-therapy peripheral blood samples collected on a monthly basis). Two of six patients with serial evaluations of greater than 1 month showed more than $10 \mathrm{NCN}$ $N P M-A L K$ transcripts at the time of diagnosis in either the bone marrow or peripheral blood samples (appendix). One patient showed high levels of NCN in both the bone marrow (580 NCN of $N P M-A L K)$ and peripheral blood (4126 NCN of $N P M-A L K)$ at the time of diagnosis. Another patient showed $38 \mathrm{NCN}$ of $N P M-A L K$ in the peripheral blood sample at diagnosis. In both patients, a decrease in NPM-ALK transcript was noted in the peripheral blood within 24-48 days and the NCN decreased over time to below levels of detection at 2 and 4 months, and remained undetectable at 5 and 8 months, respectively. In two patients, although no $N P M-A L K$ transcripts were detected at time of diagnosis, about 9 and 5 months into crizotinib therapy, $N P M-A L K \mathrm{NCN}$ was detectable within the peripheral blood, although at low levels. We do not know the significance of the absence of correlation with clinical response noted in these patients. Notably, low levels of $N P M-A L K$ transcript remain detectable at 18 months while on crizotinib therapy in two patients.

\section{Discussion}

Our results show that crizotinib, a targeted inhibitor of ALK, was well tolerated in children with recurrent or refractory cancer; that the recommended phase 2 dose of $280 \mathrm{mg} / \mathrm{m}^{2}$ twice daily was about twice the recommended adult dose; and most notably, that single-agent crizotinib therapy resulted in objective antitumour activity against recurrent or refractory paediatric malignancies harbouring $A L K$ translocations or oncogenic mutations, particularly anaplastic large-cell lymphoma. The design of this trial was similar to other recent paediatric phase 1 trials of targeted drugs, in which a molecularly selected cohort(s) of patients, postulated to derive benefit based on the biology of the underlying tumour, enrol simultaneously with the dose escalation component of the trial. The risk-benefit ratio for this strategy is favourable since the expanded cohort enrols at one dose level lower than that accruing to the phase 1 component of the trial-ie, a dose equivalent to or below the recommended phase 2 dose. Additionally, it provides an opportunity to see potential signals of antitumour activity in a patient population for which the purported target might be enriched (panel).

Marked antitumour activity was observed in patients with anaplastic large-cell lymphoma. Seven of nine children with recurrent or refractory anaplastic large-cell lymphoma, all of whom had received several previous therapies, had a complete response following crizotinib monotherapy. Anaplastic large-cell lymphoma, a distinct form of non-Hodgkin lymphoma accounting for $10-15 \%$ of all childhood lymphomas, ${ }^{22}$ has an overall 5-year event-free survival of about $70 \% .^{23-25}$ About $90 \%$ of paediatric anaplastic large-cell lymphomas contain chromosomal translocations including $A L K$, and activity of these fusion genes is necessary for cellular transformation presenting a clear therapeutic opportunity for an ALK inhibitor. We also showed the feasibility of monitoring peripheral blood with RT-PCR for the $N P M-A L K$ transcript. Because of the small size of this trial, to suggest $N P M-A L K$ will serve as a predictive molecular marker of relapsing patients with anaplastic large-cell lymphoma treated with crizotinib is premature; however previous data have shown that detection of circulating tumour cells by quantitative RT-PCR for $N P M-A L K$ is correlated with extent of disease. ${ }^{20}$ 
Another rare cancer for which accrual was enriched in this trial was inflammatory myofibroblastic tumours, a distinctive mesenchymal malignancy characterised by spindlecell proliferation with an inflammatory infiltrate. Rearrangements including the $A L K$ locus have been documented in about $50 \%$ of inflammatory myofibroblastic tumours. ${ }^{3,15,26} \mathrm{We}$ noted sustained partial responses after crizotinib treatment in patients with $A L K$ translocated inflammatory myofibroblastic tumours, evidence that supports the dependence of $A L K$-rearranged tumours on ALK-signaling, and suggests a therapeutic strategy for patients with this form of soft tissue-sarcoma. ${ }^{27}$ Previous identification of a secondary Phe1174Leu mutation, the identical sequence change that encodes for a de-novo resistance mutation in neuroblastoma, ${ }^{17}$ in a patient with inflammatory myofibroblastic tumour who received crizotinib, ${ }^{28}$ warrants close surveillance of these patients and further study of mechanisms of crizotinib resistance.

\section{Panel: Research in context}

\section{Systematic review}

There is an emerging notion in oncology that clinical efficacy can be obtained with inhibitors directed toward oncogenic receptor tyrosine kinases that are mutated or otherwise dysregulated in some tumour types. It has become clear that many human cancers activate $A L K$ signalling by creating unique oncogenic fusions of the $A L K$ gene at 2 p23 with various partners through chromosomal translocation events, ${ }^{4}$ resulting in the generation of oncogenic $A L K$ fusion genes and their encoded proteins. $A L K$ has a role in the pathogenesis of anaplastic large-cell lymphomas because of a chromosomal translocation that results in expression of an oncogenic kinase fusion protein known as NPM-ALK. Additionally, interest in ALK biology has increased considerably following the discovery of ALK translocations in a fraction of NSCLCs, and of activating point mutations within the tyrosine kinase domain of ALK in a fraction of neuroblastoma tumours. Preclinical work in anaplastic large-cell lymphoma and neuroblastoma models has shown that crizotinib potently inhibits cell proliferation. These data served as the rationale for the development of this trial.

\section{Interpretation}

The present trial suggests that antitumour activity can be obtained with crizotinib directed toward an $A L K$ pathway that is dysregulated in some tumour types, as shown by the objective responses in a high proportion of patients with anaplastic large-cell lymphoma or inflammatory myofibroblastic tumours. If these early findings are confirmed in larger phase 2 trials, crizotinib, which is now approved by the US Food and Drug Administration for first-line treatment of NSCLC with $A L K$ rearrangements, could become part of first-line therapy for paediatric tumours with ALK aberrations, including anaplastic large-cell lymphoma and neuroblastoma. Clinicians seeing these patients should consider molecular genetic profiling of the tumours and consider ALK-targeted therapy for patients with ALK-driven tumours who do not respond to conventional treatment approaches.

Part A3 of this trial enriched for patients with neuroblastoma on the basis of the discovery ${ }^{7-10}$ that $A L K$ is a potentially tractable oncogenic target in neuroblastoma. Although genetic mutation and amplification are markers of constitutive ALK activation that occur in a subset of neuroblastomas, preclinical data suggests that other mechanisms affect the sensitivity of neuroblastoma cells to ALK inhibition - eg, cells that express activation of ALK protein in the absence of a mutation or copy number aberration. ${ }^{29}$ As such, patient accrual at this stage of crizotinib development for childhood cancer was not restricted to patients with neuroblastoma with a proven ALK mutation or amplification. The objective 
responses to crizotinib recorded in two children with neuroblastoma and germline $A L K$ mutations is promising, but additional studies will be required to see whether efficacy will be recorded in children with other common somatic mutations, especially mutations that result in de-novo resistance in neuroblastoma. ${ }^{17}$

Preclinical data suggest that near complete inhibition of constitutively active $A L K$ is necessary to achieve an objective response, ${ }^{17}$ a finding similar to that observed in $B R A F$ mutant melanoma. ${ }^{31}$ Crizotinib resistance in neuroblastoma cells expressing an Phe1174 mutation probably arises, at least partly, from increased ATP-binding affinity for this mutant, which might reduce the potency of ATP-competitive inhibitors. ${ }^{17}$ Although this might be surmountable by increased exposure to crizotinib, second generation higheraffinity ATP analogues or other therapeutic strategies to target $A L K$, including immunotherapeutic approaches, are being developed to improve the therapeutic index and ideally maximise success in the clinic. Further assessment to distinguish the subset of patients with neuroblastoma who might potentially benefit from $A L K$ inhibition therapy is being done in an ongoing COG phase 2 trial (NCT00939770) for patients with proven ALK mutation or amplification. Additionally, a phase 1 COG study (NCT01606878) combining crizotinib with conventional chemotherapy is underway to provide the requisite safety and tolerability data for integrating crizotinib into frontline treatment regimens for children with high-risk neuroblastoma or anaplastic large-cell lymphoma.

This trial highlights some of the key challenges in the conduct of early phase studies with molecularly targeted agents in children with recurrent or refractory tumours, including the scarcity of available tumour tissue at the time of relapse and of validated assays at the time of trial initiation to selectively enrol patients with tumours that harbour specific molecular aberrations. In this trial, results of the correlative biology studies, assessing the $N P M-A L K$ fusion transcript in the peripheral blood from patients with anaplastic large-cell lymphoma have provided some initial insights into the pharmacodynamics of response. For patients with neuroblastoma or other solid tumours, meaningful results from correlative biology studies were not available because of the absence of tumour or other surrogate tissue for biomarker studies. The ability to acquire tumour tissue at time of relapse for research purposes is often very poor in children with solid tumours, as invasive biopsies are generally not required for diagnostic reasons, and there are ethical limitations on performing procedures with no prospect for direct benefit in children enrolling in such studies. ${ }^{31}$ Thus a limitation of this trial is that we were unable to obtain adequate archival tumour tissue to answer the secondary objective as to whether or not there is correlation between crizotinb response and an underlying somatic $A L K$ aberration.

In summary, we are in an era in which a new model for anti-cancer drug development is developing, and in which an understanding of tumour heterogeneity and molecular drivers will have an increasingly important role in the selection of the optimum treatment. More than a decade since the era of targeted therapy began with imatinib mesylate for the treatment of patients with chronic myeloid leukaemia, tyrosine kinase inhibitors are now resulting in antitumour responses in diverse populations with historically difficult-to-treat cancers. An understanding of the biology of such cancers is key to such successes. Although it is too early to know whether crizotinib will be effective in the $8-10 \%$ of children with neuroblastoma who harbour somatic $A L K$ mutations, our findings present clear evidence for efficacy for a significant fraction of children with anaplastic large-cell lymphoma and inflammatory myofibroblastic tumours.

\section{Supplementary Material}

Refer to Web version on PubMed Central for supplementary material. 


\section{Acknowledgments}

Funding for this trial was provided to the COG phase 1 and Pilot Consortium through a U01 mechanism and by Pfizer. We thank Biljana Georgievska, COG phase 1 Operations Director and the staff in the COG Operations office. We thank Per Kogner (Karolinska Institute, Stockholm, Sweden) for his patient referral.

\section{References}

1. Carpenter EL, Haglund EA, Mace EM, et al. Antibody targeting of anaplastic lymphoma kinase induces cytotoxicity of human neuroblastoma. Oncogene. 2012; 31:4859-67. [PubMed: 22266870]

2. Morris SW, Kirstein MN, Valentine MB, et al. Fusion of a kinase gene, ALK, to a nucleolar protein gene, NPM, in non-Hodgkin's lymphoma. Science. 1994; 263:1281-84. [PubMed: 8122112]

3. Katayama R, Khan TM, Benes C, et al. Therapeutic strategies to overcome crizotinib resistance in non-small cell lung cancers harboring the fusion oncogene EML4-ALK. Proc Natl Acad Sci USA. 2011; 108:7535-40. [PubMed: 21502504]

4. Griffin CA, Hawkins AL, Dvorak C, Henkle C, Ellingham T, Perlman EJ. Recurrent involvement of 2p23 in inflammatory myofibroblastic tumors. Cancer Res. 1999; 59:2776-80. [PubMed: 10383129]

5. Soda M, Choi YL, Enomoto M, et al. Identification of the transforming EML4-ALK fusion gene in non-small-cell lung cancer. Nature. 2007; 448:561-66. [PubMed: 17625570]

6. Sugawara E, Togashi Y, Kuroda N, et al. Identification of anaplastic lymphoma kinase fusions in renal cancer: large-scale immunohistochemical screening by the intercalated antibody-enhanced polymer method. Cancer. 2012; 118:4427-36. [PubMed: 22252991]

7. Chen Y, Takita J, Choi YL, et al. Oncogenic mutations of ALK kinase in neuroblastoma. Nature. 2008; 455:971-74. [PubMed: 18923524]

8. George RE, Sanda T, Hanna M, et al. Activating mutations in ALK provide a therapeutic target in neuroblastoma. Nature. 2008; 455:975-78. [PubMed: 18923525]

9. Janoueix-Lerosey I, Lequin D, Brugières L, et al. Somatic and germline activating mutations of the ALK kinase receptor in neuroblastoma. Nature. 2008; 455:967-70. [PubMed: 18923523]

10. Mossé YP, Laudenslager M, Longo L, et al. Identification of ALK as a major familial neuroblastoma predisposition gene. Nature. 2008; 455:930-35. [PubMed: 18724359]

11. Wang YW, Tu PH, Lin KT, Lin SC, Ko JY, Jou YS. Identification of oncogenic point mutations and hyperphosphorylation of anaplastic lymphoma kinase in lung cancer. Neoplasia. 2011; 13:704-15. [PubMed: 21847362]

12. Murugan AK, Xing M. Anaplastic thyroid cancers harbor novel oncogenic mutations of the ALK gene. Cancer Res. 2011; 71:4403-11. [PubMed: 21596819]

13. Grzelinski M, Steinberg F, Martens T, Czubayko F, Lamszus K, Aigner A. Enhanced antitumorigenic effects in glioblastoma on double targeting of pleiotrophin and its receptor ALK. Neoplasia. 2009; 11:145-56. [PubMed: 19177199]

14. van Gaal JC, Flucke UE, Roeffen MH, et al. Anaplastic lymphoma kinase aberrations in rhabdomyosarcoma: clinical and prognostic implications. J Clin Oncol. 2012; 30:308-15. [PubMed: 22184391]

15. Shaw AT, Yeap BY, Solomon BJ, et al. Effect of crizotinib on overall survival in patients with advanced non-small-cell lung cancer harbouring ALK gene rearrangement: a retrospective analysis. Lancet Oncol. 2011; 12:1004-12. [PubMed: 21933749]

16. Camidge DR, Bang YJ, Kwak EL, et al. Activity and safety of crizotinib in patients with ALKpositive non-small-cell lung cancer: updated results from a phase 1 study. Lancet Oncol. 2012; 13:1011-19. [PubMed: 22954507]

17. Bresler SC, Wood AC, Haglund EA, et al. Differential inhibitor sensitivity of anaplastic lymphoma kinase variants found in neuroblastoma. Sci Transl Med. 2011; 3:108ra14.

18. Christensen JG, Zou HY, Arango ME, et al. Cytoreductive antitumor activity of PF-2341066, a novel inhibitor of anaplastic lymphoma kinase and c-Met, in experimental models of anaplastic large-cell lymphoma. Mol Cancer Ther. 2007; 6:3314-22. [PubMed: 18089725] 
19. Skolnik JM, Barrett JS, Jayaraman B, Patel D, Adamson PC. Shortening the timeline of pediatric phase I trials: the rolling six design. J Clin Oncol. 2008; 26:190-95. [PubMed: 18182661]

20. Damm-Welk C, Busch K, Burkhardt B, et al. Prognostic significance of circulating tumor cells in bone marrow or peripheral blood as detected by qualitative and quantitative PCR in pediatric NPM-ALK-positive anaplastic large-cell lymphoma. Blood. 2007; 110:670-77. [PubMed: 17392503]

21. Ady N, Zucker JM, Asselain B, et al. A new 123I-MIBG whole body scan scoring methodapplication to the prediction of the response of metastases to induction chemotherapy in stage IV neuroblastoma. Eur J Cancer. 1995; 31A:256-61. [PubMed: 7718334]

22. Seidemann K, Tiemann M, Schrappe M, et al. Short-pulse B-non-Hodgkin lymphoma-type chemotherapy is efficacious treatment for pediatric anaplastic large cell lymphoma: a report of the Berlin-Frankfurt-Münster Group Trial NHL-BFM 90. Blood. 2001; 97:3699-706. [PubMed: 11389005]

23. Brugières L, Pacquement H, Le Deley MC, et al. Single-drug vinblastine as salvage treatment for refractory or relapsed anaplastic large-cell lymphoma: a report from the French Society of Pediatric Oncology. J Clin Oncol. 2009; 27:5056-61. [PubMed: 19738127]

24. Lowe EJ, Sposto R, Perkins SL, et al. the Children's Cancer Group Study 5941. Intensive chemotherapy for systemic anaplastic large cell lymphoma in children and adolescents: final results of Children's Cancer Group Study 5941. Pediatr Blood Cancer. 2009; 52:335-39. [PubMed: 18985718]

25. Le Deley MC, Rosolen A, Williams DM, et al. Vinblastine in children and adolescents with highrisk anaplastic large-cell lymphoma: results of the randomized ALCL99-vinblastine trial. J Clin Oncol. 2010; 28:3987-93. [PubMed: 20679620]

26. Shaw AT, Forcione DG, Digumarthy SR, Iafrate AJ. Case records of the Massachusetts General Hospital. Case 21-2011. A 31-year-old man with ALK-positive adenocarcinoma of the lung. N Engl J Med. 2011; 365:158-67. [PubMed: 21751909]

27. Butrynski JE, D’Adamo DR, Hornick JL, et al. Crizotinib in ALK-rearranged inflammatory myofibroblastic tumor. N Engl J Med. 2010; 363:1727-33. [PubMed: 20979472]

28. Sasaki T, Okuda K, Zheng W, et al. The neuroblastoma-associated F1174L ALK mutation causes resistance to an ALK kinase inhibitor in ALK-translocated cancers. Cancer Res. 2010; 70:1003843. [PubMed: 21030459]

29. Passoni L, Longo L, Collini P, et al. Mutation-independent anaplastic lymphoma kinase overexpression in poor prognosis neuroblastoma patients. Cancer Res. 2009; 69:7338-46. [PubMed: 19723661]

30. Bollag G, Hirth P, Tsai J, et al. Clinical efficacy of a RAF inhibitor needs broad target blockade in BRAF-mutant melanoma. Nature. 2010; 467:596-99. [PubMed: 20823850]

31. Anderson BD, Adamson PC, Weiner SL, McCabe MS, Smith MA. Tissue collection for correlative studies in childhood cancer clinical trials: ethical considerations and special imperatives. J Clin Oncol. 2004; 22:4846-50. [PubMed: 15570088] 
Table 1

Patient characteristics

\begin{tabular}{|c|c|c|c|}
\hline & Dose escalation (A1; $\mathbf{n = 4 3 )}$ & $\begin{array}{l}\text { Confirmed genetic alterations } \\
\qquad(\mathrm{A} 2 ; n=25)\end{array}$ & Neuroblastoma (A3; n=11) \\
\hline \multicolumn{4}{|l|}{ Age (years) } \\
\hline Median (range) & $11 \cdot 5(1 \cdot 9-20 \cdot 9)$ & $8 \cdot 4(1 \cdot 1-21 \cdot 4)$ & $7 \cdot 9(3 \cdot 5-14 \cdot 6)$ \\
\hline \multicolumn{4}{|l|}{$\underline{\operatorname{Sex}}$} \\
\hline Male & $24(56 \%)$ & $12(48 \%)$ & $3(27 \%)$ \\
\hline Female & $19(44 \%)$ & $13(52 \%)$ & $8(73 \%)$ \\
\hline \multicolumn{4}{|l|}{ Previous chemotherapy regimens } \\
\hline Median (range) & $2(0-8)$ & $1(0-11)$ & $1(1-8)$ \\
\hline \multicolumn{4}{|l|}{ Previous treatment } \\
\hline Radiation therapy & $23(53 \%)$ & $7(28 \%)$ & $9(82 \%)$ \\
\hline Bone marrow transplant & $11(26 \%)$ & $3(12 \%)$ & $6(55 \%)$ \\
\hline \multicolumn{4}{|l|}{ Diagnosis } \\
\hline \multicolumn{4}{|l|}{ Solid tumours } \\
\hline Ewing's sarcoma & $4(9 \%)$ & 0 & 0 \\
\hline Inflammatory myofibroblastic tumour & $2(5 \%)$ & $5(20 \%)$ & 0 \\
\hline Osteosarcoma & $7(16 \%)$ & 0 & 0 \\
\hline Neuroblastoma & $15(35 \%)$ & $8(32 \%)$ & $11(100 \%)$ \\
\hline Non-small-cell lung & 0 & $3(12 \%)$ & 0 \\
\hline Other ${ }^{*}$ & $5(12 \%)$ & 0 & 0 \\
\hline Rhabdomyosarcoma & $3(7 \%)$ & 0 & 0 \\
\hline Soft-tissue sarcoma & $2(5 \%)$ & 0 & 0 \\
\hline \multicolumn{4}{|l|}{ Lymphomas } \\
\hline Anaplastic large-cell lymphoma & 0 & $9(36 \%)$ & 0 \\
\hline \multicolumn{4}{|l|}{ CNS tumours } \\
\hline Glioma & $4(9 \%)$ & 0 & 0 \\
\hline Ependymoma & $1(2 \%)$ & 0 & 0 \\
\hline \multicolumn{4}{|l|}{$\underline{\text { Performance status }}{ }^{\dagger}$} \\
\hline 100 & $26(60 \%)$ & $9(36 \%)$ & $5(45 \%)$ \\
\hline 90 & $9(21 \%)$ & $7(28 \%)$ & $4(36 \%)$ \\
\hline 80 & $4(9 \%)$ & $4(16 \%)$ & $1(9 \%)$ \\
\hline 70 & $2(5 \%)$ & $4(16 \%)$ & 0 \\
\hline 60 & $2(5 \%)$ & $1(4 \%)$ & $1(9 \%)$ \\
\hline
\end{tabular}

Data are number of patients (\%) or median (range). Part A1=dose escalation. Part $\mathrm{A} 2=$ confirmed $A L K$ translocation, mutation, or amplification. Part A3=neuroblastoma.

*Hepatocellular carcinoma (n=2); Wilms' tumour ( $\mathrm{n}=1)$; malignant schwannoma $(\mathrm{n}=1)$; fusiform malignancy $(\mathrm{n}=1)$.

Lansky $\geq 16$ years or Karnofsky $>16$ years. 


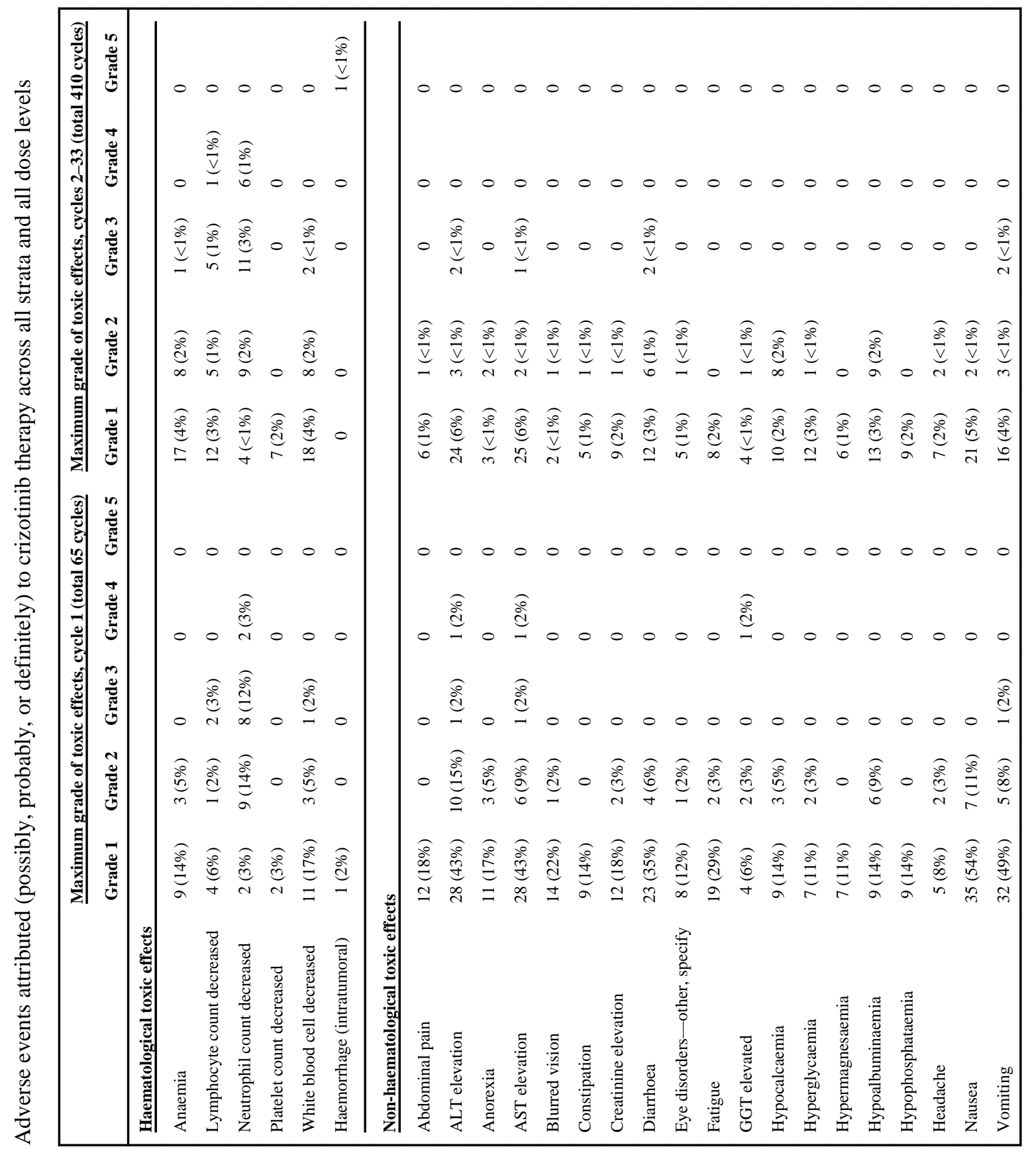




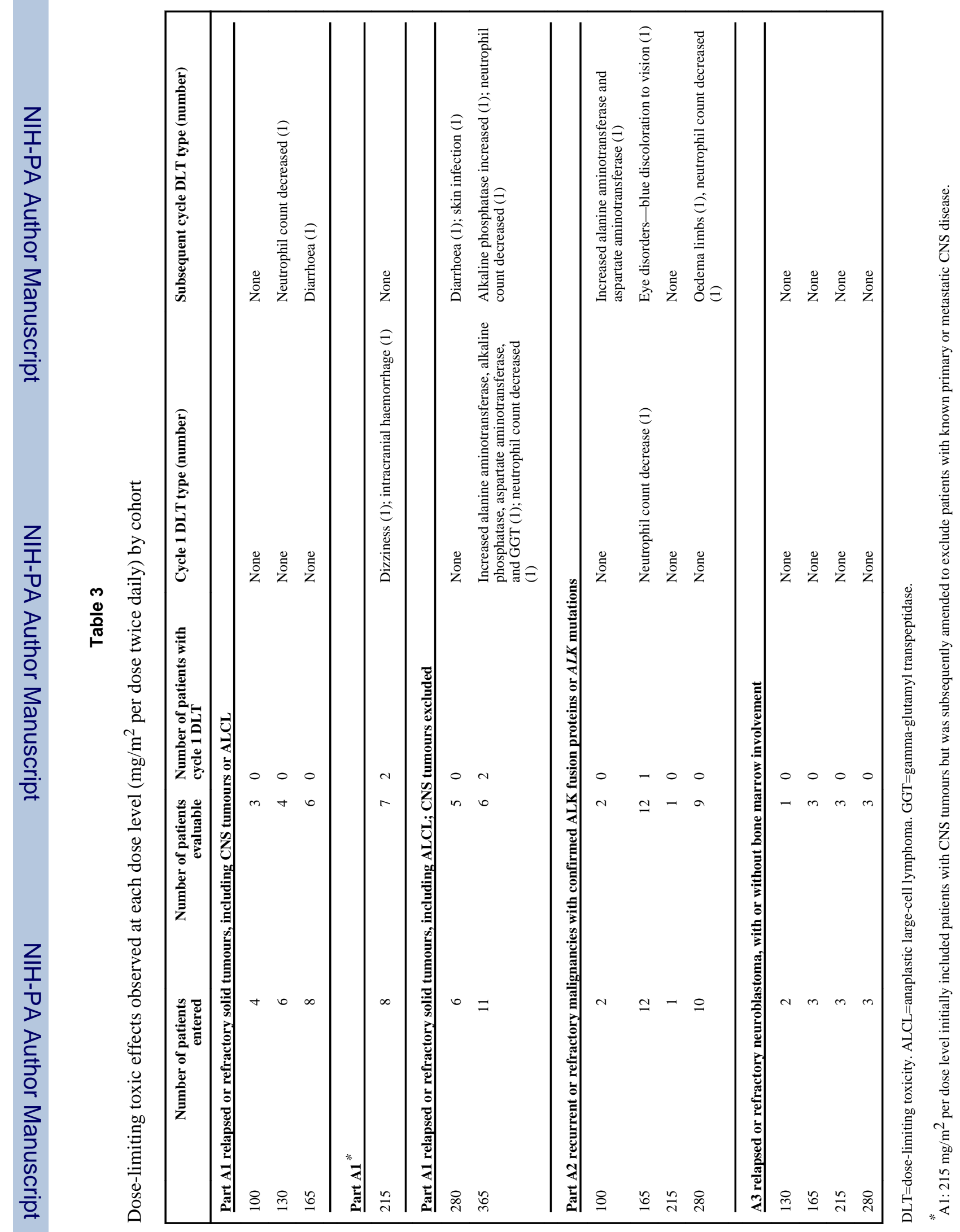

Lancet Oncol. Author manuscript; available in PMC 2013 August 01. 


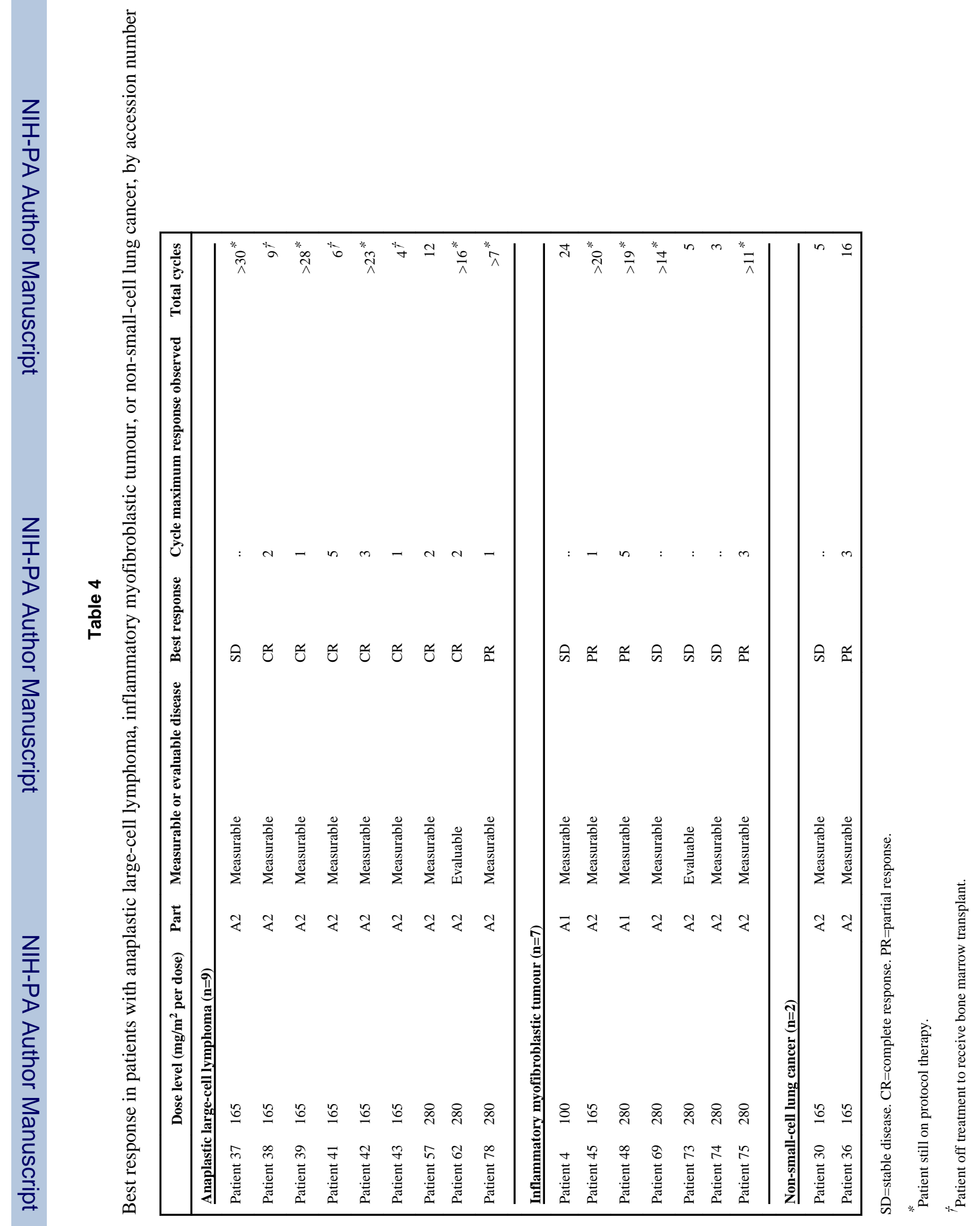

Lancet Oncol. Author manuscript; available in PMC 2013 August 01. 


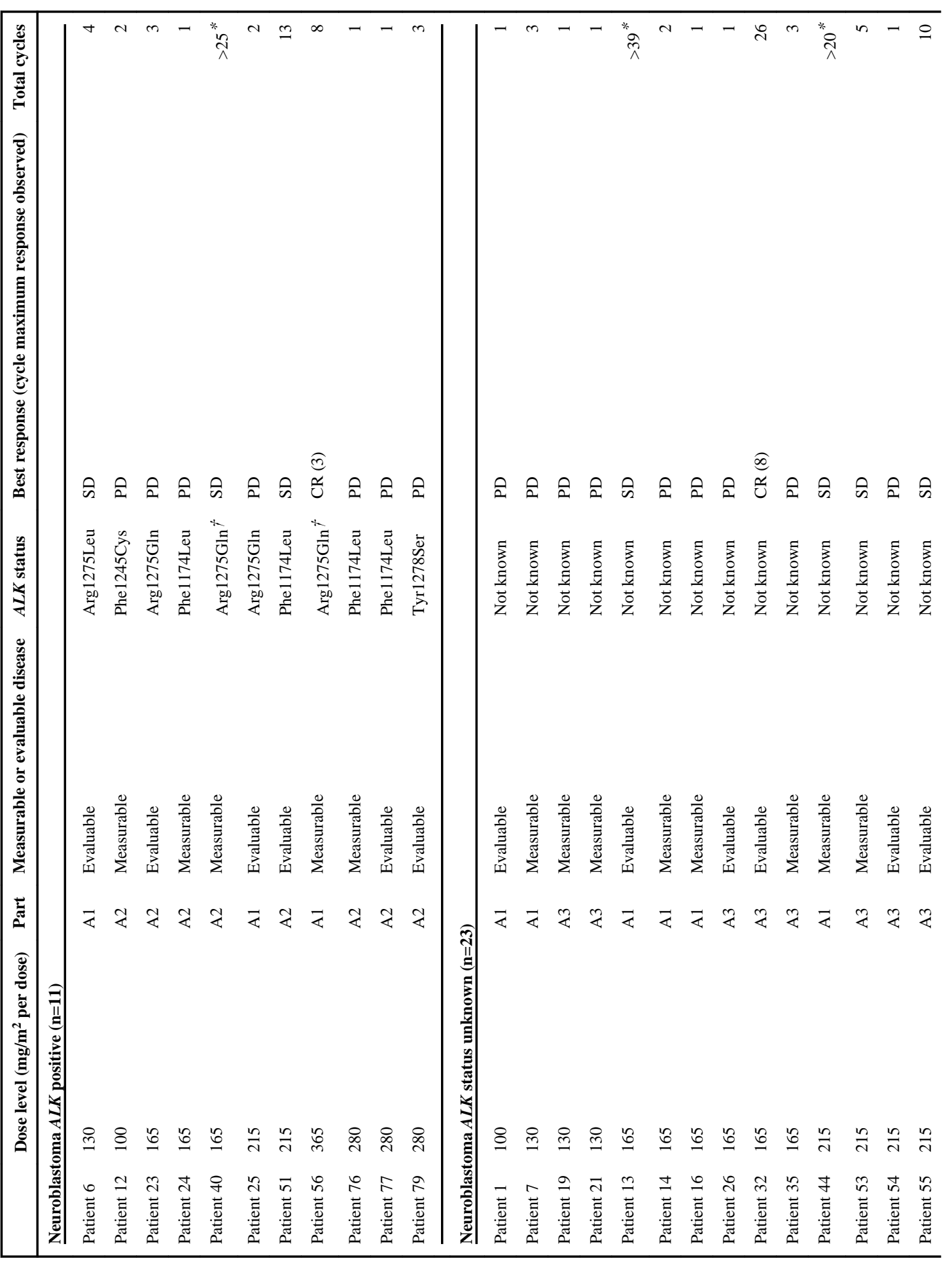




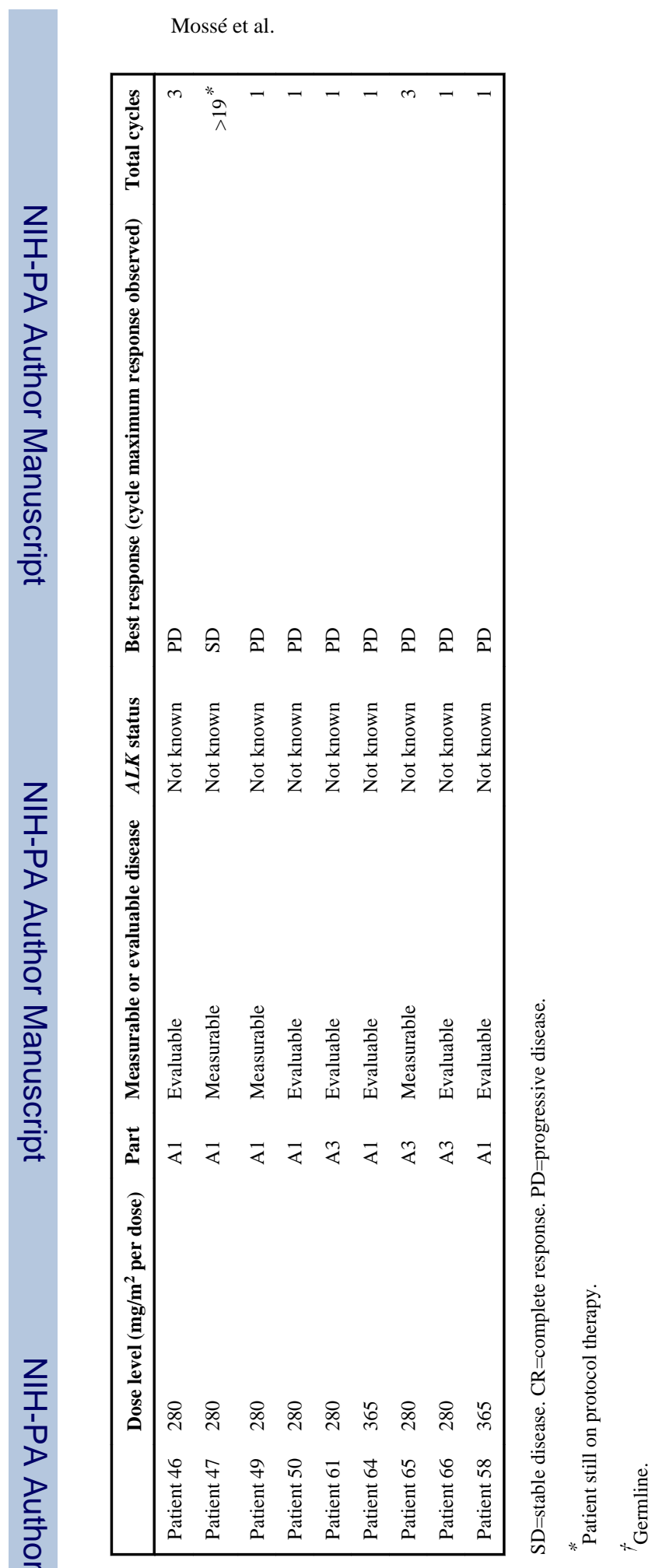

Lancet Oncol. Author manuscript; available in PMC 2013 August 01. 